\title{
Commentary: A thorough understanding of the mitral apparatus will improve the results of mitral valve repair: Part 2
}

\author{
Lorenzo Di Bacco, MD, and Antonio Miceli, MD
}

From the Department of Minimally Invasive Cardiac Surgery, Istituto Clinico Sant'Ambrogio, Milan, Italy. Disclosures: Authors have nothing to disclose with regard to commercial support.

Received for publication Oct 13, 2018; accepted for publication Oct 15, 2018; available ahead of print Nov 16, 2018

Address for reprints: Antonio Miceli, MD, Department of Minimally Invasive Cardiac Surgery, Istituto Clinico Sant'Ambrogio, Via Luigi Giuseppe Faravelli 16, 20149, Milano, Italy (E-mail: antoniomiceli79@alice.it). J Thorac Cardiovasc Surg 2019;157:1450-1

$0022-5223 / \$ 36.00$

Copyright (c) 2018 by The American Association for Thoracic Surgery

https://doi.org/10.1016/j.jtcvs.2018.10.075

Plenty of studies have aimed to clarify the geometric changes of the left ventricle (LV) after the process of remodeling, causing secondary mitral regurgitation (MR). ${ }^{1-5}$ Results are controversial. Some previous experiences found that apical displacement of the papillary muscles is the main reason of the apical tethering of the mitral leaflets; conversely, others showed no displacement of papillary muscles, especially for the posterior papillary muscle (PPM). More recently, it has been shown this muscle has a posterolateral displacement and moves toward the mitral annulus. ${ }^{1,2,6}$

In this issue of the Journal, Bothe and colleagues ${ }^{7}$ add evidence that no apical papillary muscle displacement is observed and that the displacement vector of the PPM is directed posterolaterally. From their study of an in vivo ovine 3-dimensional vector model, Bothe and colleagues ${ }^{7}$ conclude that this posterolateral displacement is the predominant mechanism leading to apical leaflet tethering during chronic secondary MR. A similar mechanism was reported by Timek and colleagues in an acute ovine model.

MR was the expression of a lateral and posterior displacement of the PPM away from the midseptal annulus with its heads, which moved toward the mitral annulus. ${ }^{1}$

Secondary MR is a disease of the ventricle and papillary muscles that leads to valve dysfunction. In this regard, Bothe and colleagues ${ }^{7}$ have focused mainly on PPM posterolateral displacement, which represents an important modification in LV geometry, leading to leaflet tethering. It would also have been interesting, however, to analyze the dynamic changes in the interpapillary muscle distance. ${ }^{4}$ During systolic closure of mitral valve, papillary muscles approximate, leading to a shortening of interpapillary muscle distance, with consequent slackness in the marginal and secondary chordae. This movement allows basal leaflet motion toward coaptation. In the setting of chronic IMR, Kalra and colleagues ${ }^{4}$ demonstrated that the loss of systolic shortening of interpapillary muscle distance can alter mitral valve force balance, resulting in asymmetric MR.

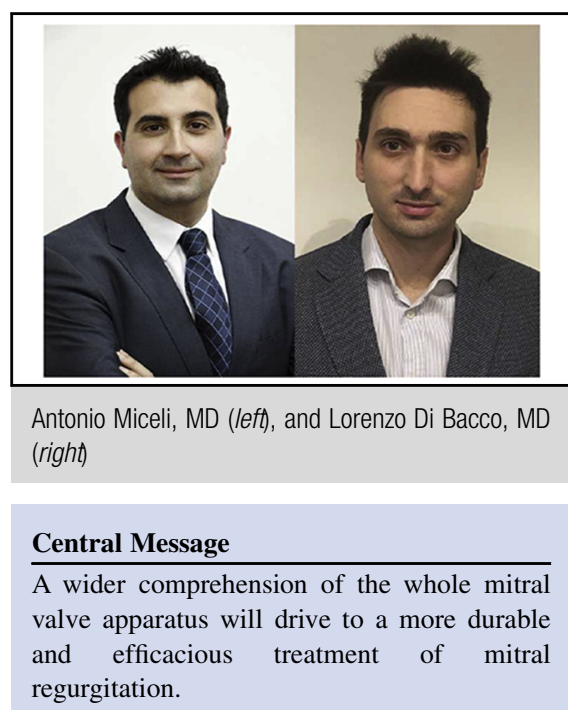

See Article page 1444.

In addition, no information has been reported regarding the impact of LV remodeling, a well-known predictor of recurrence of MR after mitral valve annuloplasty. ${ }^{6}$

Jensen and colleagues ${ }^{6}$ reported an increased distance between the anterior papillary muscle and the PPM and their asymmetric displacement after LV remodeling. Moreover, they described an apical displacement of anterior papillary muscle at end-systole, which could be explained by global LV remodeling after regional myocardial infarction. ${ }^{6}$

The most common treatment of secondary MR is mitral valve annuloplasty. Solely reductive mitral annuloplasty is destined to failure over time, ${ }^{8}$ however, because it has been associated with an increased rate of recurrent MR at 2-year follow-up. ${ }^{9}$ Nevertheless, a standard technique for the correction of the subvalvular apparatus to prevent recurrence of MR has not yet been developed.

Bothe and colleagues ${ }^{7}$ advise relocating PPMs in the presence of posterolateral displacement. Other techniques have been proposed ${ }^{10}$; however, few data are available on long-term efficacy, and no information has been reported how LV remodeling may affect the repair durability. ${ }^{11,12}$

The mitral valve is a complex structure that requires precisely timed and harmonic coordination of the LV, papillary muscles, chordae tendineae, leaflets, mitral annulus, and left atrium to achieve a competent valve closure. ${ }^{13} \mathrm{We}$ 
know that failure of any one of these anatomic components causes MR, but we are still far from a real understanding, because different studies have drawn different conclusions. As reported in a previous editorial commentary, ${ }^{13}$ we maintain that a thorough understanding of the mitral apparatus will improve the results of mitral valve repair.

\section{References}

1. Timek TA, Lai DT, Bothe W, Liang D, Daughters GT, Ingels NB, et al. Geometric perturbations in multiheaded papillary tip positions associated with acute ovine ischemic mitral regurgitation. J Thorac Cardiovasc Surg. 2015;150:232-7.

2. Gorman JH III, Jackson BM, Gorman RC, Kelley ST, Gikakis N, Edmunds LH Jr. Papillary muscle discoordination rather than increased annular area facilitates mitral regurgitation after acute posterior myocardial infarction. Circulation. 1997;96(9 Suppl):II124-7.

3. Kim K, Kaji S, An Y, Nishino T, Tani T, Kitai T, et al. Interpapillary muscle distance independently affects severity of functional mitral regurgitation in patients with systolic left ventricular dysfunction. J Thorac Cardiovasc Surg. 2014;148: 434-40.e1.

4. Kalra K, Wang Q, McIver BV, Shi W, Guyton RA, Sun W, et al. Temporal changes in interpapillary muscle dynamics as an active indicator of mitral valve and left ventricular interaction in ischemic mitral regurgitation. J Am Coll Cardiol. 2014;64:1867-79.

5. Beaudoin J, Thai WE, Wai B, Handschumacher MD, Levine RA, Truong QA. Assessment of mitral valve adaptation with gated cardiac computed tomography: validation with three-dimensional echocardiography and mechanistic insight to functional mitral regurgitation. Circ Cardiovasc Imaging. 2013;6:784-9.

6. Jensen H, Jensen MO, Smerup MH, Ringgaard S, Sørensen TS, Andersen NT, et al. Three-dimensional assessment of papillary muscle displacement in a porcine model of ischemic mitral regurgitation. J Thorac Cardiovasc Surg. 2010;140:1312-8.

7. Bothe W, Timek TA, Tibayan FA, Walther M, Daughters GT, Ingels NB, et al. Characterization of 3-dimensional papillary muscle displacement in in vivo ovine models of ischemic/functional mitral regurgitation. J Thorac Cardiovasc Surg. 2019;157:1444-9.

8. Zhu F, Otsuji Y, Yotsumoto G, Yuasa T, Ueno T, Yu B, et al. Mechanism of persistent ischemic mitral regurgitation after annuloplasty: importance of augmented posterior mitral leaflet tethering. Circulation. 2005;112(9 Suppl):1396-401.

9. Goldstein D, Moskowitz AJ, Gelijns AC, Ailawadi G, Parides MK, Perrault LP, et al; CTSN. Two-year outcomes of surgical treatment of severe ischemic mitral regurgitation. $N$ Engl J Med. 2016;374:344-53.

10. Nicolini F, Agostinelli A, Vezzani A, Molardi A, Benassi F, Gallingani A, et al. Surgical treatment for functional ischemic mitral regurgitation: current options and future trends. Acta Biomed. 2015;86:17-26.

11. Kron IL, Green GR, Cope JT. Surgical relocation of the posterior papillary muscle in chronic ischemic mitral regurgitation. Ann Thorac Surg. 2002;74: 600-1.

12. Fattouch K, Castrovinci S, Murana G, Dioguardi P, Guccione F, Nasso G, et al. Papillary muscle relocation and mitral annuloplasty in ischemicmitral valve regurgitation: midterm results. J Thorac Cardiovasc Surg. 2014;148: 1947-50.

13. Miceli A. A thorough understanding of the mitral apparatus will improve the results of mitral valve repair. J Thorac Cardiovasc Surg. 2015;150:238-9. 